\title{
Lope de Vega, Barlaán y Josafat, ed. Daniele Crivellari, Madrid, Cátedra, 2021, 360 pp. ISBN: 978-84-376-4208-6
}

\section{Giada Blasut}

http://orcid.org/0000-0001-6044-2861

Universidad Complutense de Madrid

ESPAÑA

Università di Verona

ITALIA

giada.blasut@univr.it

[Hipogrifo, (issn: 2328-1308), 9.2, 2021, pp. 1113-1117]

Recibido: 22-09-2021 / Aceptado: 04-10-2021

DOI: http://dx.doi.org/10.13035/H.2021.09.02.73

El teatro religioso de Lope de Vega ha salido del olvido que la crítica denunciaba desde casi un siglo. Es con este dato esperanzador que se abren las primeras páginas de la Introducción a la edición crítica de la comedia Barlaán y Josafat a cargo de Daniele Crivellari, publicada por la editorial Cátedra en 2021. Pero es más, no solo en los últimos cincuenta años se han ido publicando reflexiones teóricas acerca del género y estudios puntuales sobre determinadas comedias, sino que incluso han ido apareciendo obras inéditas, cuando no nuevos testimonios de alguna tradición textual. Con respecto a este último punto, el hallazgo del manuscrito autógrafo de la comedia Barlaán y Josafat -ocurrido en 2015, de la mano de Daniele Crivellari- ofrece ahora la ocasión para una nueva edición crítica de la comedia. Análogamente, el autógrafo brinda también la posibilidad de calar hondo en los versos originales escritos por Lope y de indagar cómo fueron modificados en la restante tradición textual de la comedia que se caracteriza por la condensación del tercer acto original en el segundo y por la adición de un tercer acto inédito. Según advierte el editor, el protagonista de la pieza, Josafat, sería una representación del mismo Buda, cuya historia ha ido evolucionando desde el «sutra budista Lalitavistara» (p. 15) hasta la traducción a diferentes lenguas europeas -y la agregación de otro personaje, su maestro Barlaán-, y sufrir un «proceso de cristianización» a través de algunos aspectos adicionales. A la hora de redactar su texto, el Fénix contaba por lo tanto con una rica tradición literaria en relación con este tema, de la que debió servirse como fuente de su labor de La Historia de los dos soldados de Cristo (Madrid, Juan de Arce Solorceno, 1608). 
Tras haber establecido las coordenadas principales de la Introducción, Crivellari dedica a cada una de ellas una sección específica. La primera de estas, «San Buda, venido de Oriente: Barlaán y Josafat y la comedia hagiográfica» (pp. 18-38), da prueba de por qué es posible tanto adscribir este texto al género de las comedias de santos de tipo hagiográfico, como reconocer en ella un afán innovador. Entre las primeras causas, las que integran el texto a las comedias de santos, destacan el tratamiento de la fuente arriba citada y de lo sobrenatural que se escenifica en todas las «manifestaciones» individuadas por Dassbach: «profecías y voces celestiales, visiones y apariencias, levitaciones, milagros, intervenciones angélicas, diabólicas y de otros personajes sagrados» (p. 22). Por el contrario, otros aspectos hacen que esta comedia trascienda el paradigma al que se adscribe: el actuar de Barlaán tanto en compañía de Josafat como en solitario; los personajes alejados espacial y cronológicamente del público; la estricta adhesión a la unidad de acción; y el tríplice conflicto - señalado por García Reidy - que afecta lo generacional, religioso y sentimental (de cuyo último aspecto Lope se sirve también para añadir dentro de la acción principal, y no al lado, otra secundaria protagonizada por Leucipe). Crivellari completa brillantemente esta primera sección analizando el estrecho vínculo que Lope enlaza en la pieza entre «palabra y representación, por un lado, y entre narración y descubrimiento de la realidad, por otro» (p. 28). Como argumenta el editor, el empleo del romance al servicio de la narración se entiende no solo si se considera el rol que desempeña en la descripción de la realidad para Josafat y otros personajes, sino también como instrumento que favorece al público la información que ignora; así, «función narrativa y de revelación de la realidad» se unen en esta forma métrica (pp. 29-38).

El apartado siguiente, «El manuscrito autógrafo: Lope (y la compañía de actores) ante el texto» (pp. 38-59), atesora un análisis filológico de primer orden dedicado a la constelación de datos que los manuscritos autógrafos dramáticos lopescos custodian y a la que Daniele Crivellari ha dedicado a lo largo de los años numerosos y detallados estudios, amén de una monografía. El editor abre esta sección argumentando la naturaleza del presente documento autógrafo en la base de los diferentes errores de copia detectados en él. El manuscrito de Barlaán y Josafat es, al igual que otros documentos redactados por el Fénix, una copia en limpio de un borrador anterior, un texto antígrafo, que hoy en día ya no se conserva. Sin embargo, el editor explica que en el autógrafo tampoco faltan pasajes pensados e insertados ex novo durante la fase de transcripción, ni intervenciones efectuadas sobre la marcha para mejorar algún fragmento del texto. Finalmente, la sección se cierra con la descripción de un objeto de estudio largamente indagado por Crivellari: las modificaciones atribuibles a la compañía que representó la obra -supuestamente la de Hernán Sánchez de Vargas - que están vinculadas con su puesta en escena (reducción de algunas estrofas, redistribución de los parlamentos a los personajes a raíz del número de actores disponibles) cuando no con la voluntad de sanar pequeños despistes de Lope.

Una vez que se han analizado las diferentes fases de redacción de la obra (copia del texto principal, modificación en el acto de transcripción de algunos pasajes y sucesiva corrección de la comedia) y de los cambios aportados por la compañía 
teatral para subirla al tablado, el estudio introductorio prosigue, fiel al usus de la época, describiendo la siguiente etapa de difusión de la pieza: la publicación en letras de molde. El apartado «Avatares de la comedia entre reelaboraciones, huellas y representaciones» (pp. 59-71) profundiza en el texto impreso que salió en 1641 en la Parte XXIV de las comedias del Fénix. Para definir este testimonio Daniele Crivellari prefiere, frente al concepto de «refundición», el de «reelaboración» propuesto por Ruano de la Haza porque el impreso, contrariamente a las «refundiciones», no exhibe un texto nuevo plasmado a raíz de aspectos que ya aparecían en un texto anterior, sino una «nueva versión» del mismo, lo que le convierte en una «reelaboración» de la obra (p. 60). Súmense además otras dos cuestiones de gran interés que afectan al impreso: la autoría del texto y el motivo de su alteración, cuya manifestación mayor se concreta en un nuevo tercer acto a expensas del original que se condensa en el segundo. Respecto a este último punto, Crivellari desvela cuáles son las principales estrategias empleadas en los primeros dos actos del impreso: respectivamente, reducción, eliminación y simplificación; y «supresión, sustitución y desplazamiento» (p. 61); así como las peculiaridades más destacadas del último acto añadido que la crítica no atribuye a Lope. A continuación, el editor destaca cómo, una vez más, la trayectoria vital de la comedia reflejada en el autógrafo es capaz de arrojar luz sobre las transformaciones de la pieza en la base de algunos cambios presentes en el impreso que ya se habían insertado en el original de Lope para la representación de la pieza, como ocurre con algunos pasajes tachados en el autógrafo ausentes también en 1641. Del mismo modo, otras modificaciones de la edición de 1641 encuentran su génesis en la compañía teatral como ocurre, por ejemplo, con las tres peculiaridades del tercer acto añadido: el distanciamiento de la fuente, la espectacularidad y el «protagonismo de Leucipe» (pp. 64-65); atributos que para Crivellari no constituyen de por sí pruebas de que Lope no escribió este texto, pero son, parafraseando al editor, elementos extraños, en otros términos, índices de un cambio de rumbo radical y, por consiguiente, de una ruptura en la coherencia de la comedia. Esta hipótesis se vería respaldada incluso por otras particularidades de la compañía: la disposición de un «decorado especial» que se quiere utilizar - argumento aportado por Ruano de la Haza-, y el número de actores que la componen y que conlleva, por un lado, la intervención de personajes ausentes en el original (ejemplifica esta situación con el gracioso), y, por otro, un mayor protagonismo de la autora y primera dama, Polonia Pérez (p. 66). Con todo, y con el cometido de ofrecer una conclusión provisional al problema - pendiente, quizás, de nuevos estudios ortoépicos-, Daniele Crivellari individúa al autor de la refundición en el director u otro miembro de una compañía teatral. Las últimas páginas de la sección están dedicadas a la relación con La vida es sueño de Calderón que se reduce a una limitada proximidad, tanto de algunos temas (profecías astrológicas, el estado social de los protagonistas y la ignorancia del "ser femenino»), como de algunos pasajes concretos de los dos textos. Encima, la existencia de un tercer acto añadido, supuestamente no redactado por Lope, abre la vía a una nueva consideración: ¿pudo Calderón inspirarse ya no en la obra del Fénix sino en la refundición de 1641? Lo cierto es que en la época los textos que circulaban sobre esta leyenda 
no eran escasos y Calderón disponía, como anteriormente Lope, de una vasta tradición literaria que prosperará incluso durante las dos centurias sucesivas; señal evidente del éxito de la historia, al igual que del gusto del público contemporáneo.

La sección siguiente, «Descripción de los testimonios e historia textual» (pp. 71 80), ofrece una descripción de la tradición textual de la comedia Barlaán y Josafat; al manuscrito autógrafo $(O)$ se suman dos ediciones antiguas - una publicada en 1641 en la Parte XXIV de las comedias de Lope $(P)$ y una suelta sin fechar $(S)$ - , y un manuscrito $(M)$ donde destacan la remodelación de los últimos dos actos en el segundo y la adición de un tercer acto inédito. Atención se reserva también a las ediciones modernas del texto desde la pionera de Menéndez Pelayo (1894) hasta la transcripción del texto de 1641 ofrecida en la base de datos TESO, pasando por la que emplea, al igual que la que aquí se reseña, el autógrafo como texto base de la edición: la que publicó en 1935 José Fernández de Montesinos. Por fin, Crivellari reanuda minuciosamente, y señalando los respectivos versos, las variantes textuales que le han permitido señalar dentro de la tradición textual la rama constituida por $P, S$ y $M$, cuyo orden bien refleja su relación lineal: el manuscrito deriva de la suelta que a su vez procede de $P$. Por lo que interesa al vínculo entre el autógrafo y el texto impreso en $1641(P)$ y, como se ha indicado en un apartado precedente, es cierto que el segundo es una refundición del primero, si bien queda por descubrir si otros testimonios se interponen entre ellos.

La Introducción termina con la larga y minuciosa sección intitulada «Sinopsis métrica y argumental; segmentación de la obra» (pp. 80-118) donde Crivellari informa acto por acto de las formas métricas de la comedia, especificando también el dato total y en porcentaje de cada metro (pp. 83-84). Del mismo modo, se exponen también las formas métricas del tercer acto añadido presente en la restante tradición textual: $P, S, M$ (pp. 83-84). Seguidamente, el editor ofrece un detallado resumen de la pieza cuya división en párrafos, encabezados por la indicación del verso empleado, bien evidencia su polimetría que, según recuerda Crivellari, delimita -junto con un sistema de rayas autógrafas del manuscrito original, el espacio, el tiempo, los momentos de tablado vacío y la acción dramática - la segmentación en cuadros y microsecuencias de la obra (pp. 84-101). Acto seguido, el editor ofrece, primeramente, una buena muestra de la estructura tripartita la comedia - cada uno de los tres actos estaría constituido por tres cuadros a su vez divisibles en otras tantas microsecuencias-, y, a continuación, se detiene en las rayas autógrafas detectadas en el original lopesco para explicitar sus funciones en la segmentación de la pieza.

La edición crítica anotada propiamente dicha de la comedia Barlaán y Josafat (pp. 147-283) sigue criterios editoriales establecidos a partir de los que ha definido el grupo de investigación Prolope (pp. 119-122), y viene completada por un Apéndice final donde se publican: el «Acto tercero» que consta en P, S y M (pp. 287-328), el «Aparato de variantes» (pp. 329-351) y las «Características del autógrafo» (pp. 351358). La anotación, colocada en el pie de página del texto crítico de la comedia y del tercer acto añadido, es apta para una eficaz comprensión de la pieza desde el punto de poético al igual que dramático. Como es usual en este tipo de labor editorial, en 
las notas se aclaran aquellos pasajes del texto de difícil interpretación, así como los términos que en un determinado contexto adquieren un significado diferente del habitual. Tampoco escasean consideraciones de tipo métrico y lingüístico ni filológico, especialmente cuando se rechaza la lectura del texto base, el manuscrito autógrafo de Lope - cuya lectura se pospone en estos casos al «Aparato de variantes»- a favor de la lectio que transmite la restante tradición textual. Pero el dato quizás más brillante de esta nueva edición de Barlaán y Josafat es la capacidad de hacer dialogar las contribuciones ya evidenciadas por la comunidad científica con las novedosas aportaciones de Crivellari, quien aprovecha todos los avances de la moderna filología y de los estudios sobre la literatura dramática áurea para informar tanto de los pormenores poéticos de la comedia como de su vertiente dramática, o sea, la puesta en escena ante el público áureo.

Para terminar, la publicación de Daniele Crivellari conjuga al mismo tiempo una edición crítica fiable de la comedia y un estudio introductorio capaz de dirigirse a un público vasto y heterogéneo mediante la capacidad de proyectar, al igual que un prisma, las múltiples perspectivas de estudios que ofrecen el teatro español del Siglo de Oro y los textos autógrafos del Fénix de los ingenios. 